\title{
ESTRATÉGIAS DE PROGRESSÃO REFERENCIAL EM TEXTOS DE ALUNOS DO PARFOR
}

\author{
ESTRATEGIAS DE PROGRESIÓN REFERENCIAL EN TEXTOS DE ESTUDIANTES DEL PARFOR \\ REFERENTIAL PROGRESSION STRATEGIES IN THE TEXTS OF STUDENTS OF THE PARFOR
}

\begin{abstract}
Antônia Alves Pereira*
IEL - UNICAMP

RESUMO: Este artigo discute estratégias de progressão referencial usadas por alunos de Letras-Língua Portuguesa do programa PARFOR. Abordamos a questão do ponto de vista sociocognitivo. Partimos de algumas questões sobre referenciação surgidas no seio da literatura especializada,dentre elas, a concepção de referente que nos leva a discussão sobre língua sistema vs.língua interação. Na sequência, identificamos como esses alunos/professores faziam evoluir o referente ao longo de seus textos. Nossa pesquisa revelou que muitas estratégias por eles adotadas são próximas daquelas utilizadas em texto de natureza não formal, isto é, não fazem parte do gênero acadêmico.
\end{abstract}

PALAVRAS-CHAVE: progressão referencial; aluno; ensino; texto.

RESUMEN: En este artículo se analizan las estrategias de progresión referencial usadas por estudiantes del Programa PARFOR Programa de Portugués y Literatura- a partir de una perspectiva socio-cognitiva. Partimos de algunas preguntas sobre el hacer referencial surgidas dentro de la literatura, entre ellas el concepto de referente, que nos lleva a la discusión de la interacción lingüística del sistema x sistema del habla. A continuación, identificamos como estos estudiantes/profesores hacen evolucionar el referente de sus textos. Nuestra investigación reveló que muchas de las estrategias adoptadas por ellos están cerca de los empleados en textos de naturaleza no formal, es decir, no hacen parte del genero académico.

PALABRAS CLAVE: progresión referencial; estudiantes; educación; texto.

ABSTRACT: This article discusses referential progression strategies used by students in the PARFOR-Portuguese Undergraduate Course. The issue is approached from a socio-cognitive point of view. Questions about reference that have emerged from the literature (among them the concept of referent) are discussed, followed by a discussion of language system vs. language interaction. We then identify how the students/teachers develop referents throughout their texts. Our research revealed that many strategies adopted by the students are very similar to those used in non-formal texts, i.e. texts that are not part of the academic genre.

KEYWORDS: referential progression; student; teaching; text.

\section{INTRODUÇÃO}

Este artigo tem como objetivo discutir as estratégias de progressão referencial usadas por alunos do PARFOR $^{1}$. O corpus é constituído por textos escritos formais e de natureza argumentativa, cujos autores são alunos do primeiro semestre do curso de Letras-Língua Portuguesa e professores da Educação Básica em vários municípios dentro do estado do Pará. Primeiramente, procuramos identificar como esses alunos/professores fazem evoluir o referente e, na sequência,analisamos os processos envolvidos na evolução. A nossa análise se pauta no domínio do gênero acadêmico, na modalidade escrita, por esses alunos.

O gênero acadêmico contém algumas características que são constantes nos textos apresentados na academia. Dentre essas características, ressalta-se a objetividade, a clareza e o uso da língua na modalidade padrão. Foi a partir dessa ideia de gênero que selecionamos o corpus desta pesquisa.

Este trabalho parte de uma visão sociocognitivo-interacional de língua, segundo a qual o discurso é o lugar de interação em queos sujeitos se constroem e são construídos ao longo de todo processo de interação (cf. $\mathrm{KOCH}, 2005)$. Os pressupostos teóricos, aqui, adotados se encontram em Koch e Elias (2010;2009); Koch

\footnotetext{
* Graduada em Letras (UFPA), Mestrado em Letras (UFPA), Doutorado em Linguística (UNICAMP) e Pós-doutorado na área de linguística em andamento (UNICAMP).Email: antoniaapp@hotmail.com
}

${ }^{1}$ O PARFOR é em sua concepção:“Um plano emergencial, que visa a assegurar a formação exigida na Lei de Diretrizes e Bases da Educação Nacional (LDB, 1996) para todos os professores que atuam na rede pública de educação básica, oferecendo, gratuitamente, cursos superiores de qualidade” (MEC, 2011). 
(2006; 2003; 2002; 1997; 1987), Koch eMarcuschi (2008; 1998); Marcuschi (2008;2001); Cavalcante(2003); Apothéloz e Reichler-Beguelin (1995); Apothéloz (2003); Mondada (2002; 2001; 1994) e Mondada eDubois (1995).

Com este enfoque, o artigo está dividido em três partes. Na primeira, discutimos a referenciação e a progressão referencial com base na literatura da área. Na segunda parte, apresentamos as estratégias de referenciação e progressão referencial, adotadas pelos alunos do PARFOR. Na sequência, discutimos os resultados tomando comobase a revisão da literatura. E, na última parte, apresentamos as considerações finais.

\section{NOTA SOBRE REFERENCIAÇÃO E PROGRESSÃO REFERENCIAL}

A referenciação é uma atividade discursiva e como tal está estritamente relacionada à cognição. Partindo desse pressuposto teórico, encontrado em obras de autores como Mondada, Mondada e Dubois, Koch,Apothéloz e Reichler-Beguelin,não se pode conceber uma visão referencial de língua. Para Koch (2002, p.79), "A realidade é construída, mantida e alterada não somente pela forma como nomeamos o mundo, mas, acima de tudo, pela forma como, sociocognitivamente, interagimos com ele”. E,conforme Mondada (2001, p. 9, tradução nossa), a referência²:

Não privilegia a relação entre as palavras e as coisas, mas a relação intersubjetiva e social no seio da qual as versões do mundo são publicamente elaboradas, avaliadas em termos de adequação às finalidades práticas e às ações em curso dos enunciados.

Adotado esse pressuposto, a concepção de língua assumida, aqui, é a sociocognitivo-interacional, que privilegia o sujeito e seus conhecimentos em processo de interação, conformeKoch e Elias (2010). Nessa perspectiva, o referente é construído no discurso como uma representação do que existe na realidade mundana, cuja representação parte da relaçãoentre língua e práticas sociais, que se materializam no uso da língua.

A referenciaçãose manifesta no discurso e a serviço do discurso, ou seja, não é estática ou dada. Para Mondada (1994, p. 62, tradução nossa $)^{3}$ :

No seio das operações de referenciação, os interlocutores elaboram os objetos de discurso, isto é, as entidades que não são concebidas como as expressões referenciais em relação espelhada com os objetos do mundo ou com suas representações cognitivas, mas as entidades que são interativa e discursivamente produzidas pelos participantes ao longo de sua enunciação. Os objetos do discurso são, pois, entidades constituídas no e para as formulações discursivas dos participantes: é no e pelo discurso que são postos, delimitados, desenvolvidos, transformados os objetos de discurso que não lhe preexistem e quenão têm uma estrutura fixa, mas que ao contrário emergem e se elaboram progressivamente na dinâmica discursiva.

Dessa forma, com o avanço dos estudos linguísticos no campo da referenciação,as noções de língua e de referência são ampliadas no âmbito da Linguística textual, já que ambas ganham um statusdinâmico,deixando, assim, de serem vistas como fundamentalmente estáticas, como no estruturalismo linguístico, vertente predominante em períodos anteriores.

O processo de progressão referencial dá-se através de estratégias variadas. Os objetos-de-discurso são construídos e reconstruídos ao longo da atividade discursiva. As formas como são construídos ou reconstruídos estão intrinsecamente relacionadas a propósitoscomunicativos do produtor do texto, como afirmam Koch e Elias (2010, p. 133-134). São escolhas orientadas pelo princípio de subjetividade. Ressaltamos, no entanto, que, mesmo quando o autor, por questões subjetivas, não queira ser explícito, isso precisa ficar claro ao leitor/ouvinte.

\footnotetext{
2"Elle ne privilégie pas la relation entre les mots et les choses, mais la relation intersubjective et sociale au sein de laquelle des versions du monde sont publiquement élaborées, évaluées en termes d'adéquation aux finalités pratiques et aux actions en cours des énonciateurs" (MONDADA, 2001, p. 9).

3“Au sein de ces opérations de referentiation, les interlocuteurs élaborent des objets de discours, i. e. des entités qui ne sont pas conçues comme des expressions référentielles emrélation speculaire avec des objets du monde ou avec leur répresentation cognitive, mais desentités qui sont interactivement et discursivement produites par les participants au fil de leurénonciation. Les objets du discours sont donc des entités constituées dans et par les formulationsdiscursives des participants: c'est dans et par le discours que sont posés, delimités, developpéset transformés Des objets de discours qui ne lui préexistent pas et qui n'ont pas unestructure fixe, mais qui au contraire émergent et s'élaborent progressivement dans la dynamiquediscursive"(MONDADA, 1994, p.62).
} 
Segundo ApothélozeBéguelin (1995, p.246), pode-se distinguir dois conjuntos de estratégias que propiciam a evolução anafórica do referente:o objeto de discurso, ao ser retomado anaforicamente, exibe transformações, isto é, a anáfora opera transformações no objeto de discurso designado. As recategorizações são exemplos desse tipo de estratégia. Na segunda estratégia, o objeto-de-discurso é retomado anaforicamente, como no seu estado inicial, ou seja, sem transformações ou acréscimos.

Verificaremos, a seguir, as estratégias de progressão textualmais encontradas em textos de alunos do PARFOR.

\section{ESTRATÉGIAS DE REFERENCIAÇÃOUSADAS NA PROGRESSÃO REFERENCIAL PELOS ALUNOS DO PARFOR}

As análises feitas nos textos de alunos do PARFOR apontam para a reiteração através de expressões nominais e para a anáfora diretacomo estratégias mais utilizadas na progressão referencial. Na sequência, discutimos essas análises.

\subsection{PROGRESSÃO REFERENCIAL E ANÁFORA CORREFERENCIAL CO-SIGNIFICATIVA}

Conforme Apothéloz (2003, p. 61), pode-se afirmar que há correferência entre duas expressões quando designam o mesmo referente no discurso.

A anáfora correferencialco-significativa se refere ao tipo de anáfora cuja realização se dá através da reiteração de termos. Esta pesquisa revelou queesta estratégia é largamente utilizada pelos alunos do PARFOR-Língua portuguesa. A seguir, apresentamos exemplos do uso desse tipo de anáfora nos textos dos alunos citados ${ }^{4}$ :

(1) "O professor enquanto mediador tem que ter metodologias precisas para atender o processo ensinoaprendizagem. Logo, faz-se necessário o processo avaliativo. Uma vez detectado as deficiências na aprendizagem é feita uma avaliação mediadora, o professorvai refazer suas práticas pedagógicas oportunizando o educando de suprir as necessidades de aprendizagem.

\section{$[\cdots]$}

A progressão automática pode-se colocar a escola num patamar de desvalorização do ensino e como tudo pode a escola passa a ser vista como uma passagem e não um lugar de aprendizagem, de busca, de mediação entre docentes e discentes.

A progressão automática pode causar sérias consequências para o aluno no futuro, ele ser aprovado para uma série que não atende as habilidades básicas para desenvolver seus estudos, vai estar atrofiado, sentindo despreparado para avançar em seus estudos".

(2) "A escola é uma instituição democrática onde se prepara cidadãos competentes para ocupar um lugar no mercado de trabalho. Isso porém, depende do compromisso em que cadaescola desempenha com a educação de seus alunos".

Os exemplos (1) e (2) mostram a evolução dos referentes através da repetição. No primeiro texto, a repetição da referência escola se dá no interior do parágrafo. E a reiteraçãoda referência progressão automática se dá em parágrafos distintos. Em (1), o termo professor se repete e fazprogredir o referente. Em (02), há a repetição da palavra escola, mas a retomada desse referente difere das repetições que se tem em (01). Conforme observamos, em (02), a palavra escola vem acompanhada do pronome cada, distinguindo, pois, a segunda ocorrência da palavra escola da primeira.

Koch e Elias (2010, p. 161) explicam que "Esse tipo de recorrência tem sidofrequentemente considerado vicioso e, por isso, condenado. O que ocorre, na verdade, é que a repetição é um poderoso recurso retórico. Portanto, há repetições 'viciosas' e repetições enfáticas, retóricas”.

A recorrência dos termos como usada nos textos acima, mesmo com propósito de fazer progredir o texto, através da evolução do referente,não é recomendada, principalmente, por trata-se de textos formais de

\footnotetext{
${ }^{4}$ Os textos dos alunos não sofreram alteração.
} 
professores da Educação Básica. Assim, é necessário o uso de novas estratégias de referenciação e progressão por esses alunos/professores.

Trabalhamos com a hipótese inicial de que a dificuldade que esses alunos/professores enfrentam na produção de textos escritos, no gênero acadêmico, está diretamente relacionada a um contato precário que tiveram com textos escritos dessa natureza. Parece estranha uma hipótese como essa quando se trata de profissionais de Língua Portuguesa, entretanto, não o será se verificarmos que suas práticas docentes ainda são pautadas no ensino da língua nos moldes da gramática tradicional- que parte da concepção de língua enquanto sistema, em que o ensino da nomenclatura gramatical é o privilegiado em detrimento do ensino da leitura e da escritasendo esses alunos/professores reflexos de práticas educativas e curriculares do Ensino Médio que têm sido alvo de constantes debates sobre o ensino da língua materna, da leitura e da escrita, adicionadas a questões da escola pública brasileira.

Características típicas da oralidade são encontradas frequentemente em seus textos escritos de natureza formal. A reiteração é uma forte característica dessa modalidade e é um dos recursos mais utilizado na progressão referencial nos textos escritos por esses alunos.

Não é nossa intenção nos debruçarmos sobre as características das modalidades oral e escrita, dado que foge ao foco desse trabalho. No entanto, para melhor situar o leitor, faremos um breve registro sobre elas.

Durante muito tempo, as diferenças entre as modalidades oral e escrita foram tratadas, na linguística, como estanques. A modalidade oralera vista como relaxada, descontextualizada etc.; ao passo que a escrita era cuidadosamente tratada, planejada, contextualizada etc..

Com o avanço de estudos nessas áreas, um novo olhar foi lançado sobre a questão. No Brasil, Marcuschi é um dos estudiosos pioneiros. Conforme esse autor, "As diferenças entre fala e escrita se dão dentro do continuum tipológico das práticas sociais e não na relação dicotômica de dois pólos opostos” (MARCUSCHI, 2001b, 37). Atualmente, é a visão mais aceita entre os estudiosos dessa temática.De acordo com ela, as modalidades oral e escrita se apresentam de forma análoga se seus contextos de produção são semelhantes.

Entretanto, estudiosos que assumem esse ponto de vista também concordam que as duas modalidades apresentam características próprias, que as distinguem: "Fala e escrita são duas modalidades de uso da língua, possuindo cada uma delas características próprias" (KOCH, 1997, p.31).

Em relação à repetição nas duas modalidades, essa autora se posiciona da seguinte forma: "No texto falado, a repetição ocorre com extrema frequência, podendo mesmo ser considerada um dos mecanismos organizadores dessa modalidade textual; no texto escrito ela é menos frequente, desempenhando, em geral, funções didáticas, argumentativas, enfáticas, etc.” (KOCH, 1997, p.35).

Como dissemos anteriormente, partimos da hipótese de que esses alunos/professores ainda usam a repetição, estratégiade produção textual mais fortemente presentena modalidade oral, por ser ainda a mais conhecida por eles, dado que usada regularmente.

\subsection{PROGRESSÃO REFERENCIAL E RECATEGORIZAÇÃO DO REFERENTE}

Nessa parte, analisaremos a estratégia de progressão referencial através da recategorização do referente. A recategorização, de acordo comApothéloz (1995), pode ser tomada como uma categoria fundamental para explicar os processos de heterogeneidade semântica no processamento textual, isto é, como estratégia produtora de coerência e coesividade implícitas.

A progressão referencial com recategorização do referente diz respeito aum processo de referenciação que retoma uma referência anterior operando transformações nela.

Para Cavalcante (2003, p. 109), há recategorização lexical "quando uma forma referencial for renomeada no discurso, a fim de se adaptar aos objetivos comunicacionais persuasivos do enunciador".

A seguir, mostramos como essa estratégia é utilizada em textos de alunos do PARFOR: 
(3) “Desde o momento que a criança ingressa no âmbito escolar é possível obtermos informações sobre o que $o$ aluno aprendeu, de que forma e em quais condições [...] observa-se que seria mais viável ao tema, a diminuição de reprovação nas escolas, ao invés da eliminação da reprovação, uma vez que a aprendizagem do alunado não acontece na mesma proporção".

(4)“ A eliminação da reprovação é um fator influenciados pelo nossos governantes, que são os políticos, porque visa o lucro da educação em troca de dinheiro na rede pública”.

(5) “[...] A eliminaçãa vai depender de vários fatores, é considerar não as capacidades intelectuais e os conhecimentos de que os alunos dispõem, mas também seus interesses e motivações [...]”.

Em (3), o objeto-de-discurso a criança, que aparece na linha 1, é retomado na linha 2, através do nomealuno. Tem-se, aqui, um nominal mais geral, criança, que é substituído por um mais específico, aluno. Sabemosque nem toda criança é aluno no sentido empregado, aqui, para esse termo. Tem-se, nesse caso, uma recategorização do referente. Um hipônimo (aluno) é correferencial com seu hiperônimo (criança). Essa relação anafórica é chamada porKoch (2005) anáfora correferencialrecategorizadora.

Percebemos em (04), a introdução do objeto-de-discurso nossos governantese, na sequência, uma expressão definidora os políticos retomando esse objeto-de-discurso.Jáem (05), é um nome genérico fatores que se encontra em relação anafórica comcapacidades, conhecimentos, interesses e motivações.

Através dos textos analisados, ficou evidenciado para nós que a progressão referencial através da recategorizaçãonão é utilizada em larga escala pelos alunos do PARFOR.

3.3. PROGRESSÃO REFERENCIAL E ANÁFORA PRONOMINAL

Conforme Milner (2003, p. 94):

Há relação de anáfora entre duas unidadesA e Bquando a interpretação de B depende crucialmente da existência de A, a ponto de se poder dizer que a unidade B só é interpretável na medida em que ela retoma- inteira ou parcialmente- A. Esta relação existe quando B é um pronome cuja referência virtual só se estabelece pela interpretação de um N" que o pronome 'repete'.

Ainda segundo esse autor, a anáfora pronominal usual tomada em si mesma é a combinação da correferênciae da retomada.É uma concepção estreita de anáfora adotada também porKleiber (2001) e Halliday (1985). Conforme Lima (2003, p. 136), os partidários dessa concepção veem a anáfora como um fenômeno fundamentalmente ligado à coesão textual e caracterizado pela retomada de um segmento de textopor outro.

Autores como Apothéloz (2003) e Marcuschi e Koch (2002) partem de uma definição mais ampla para a concepção da anáfora. Conforme Apothéloz (2003, p.57), formulações segundo as quais um anafórico se refere a seu antecedente devem ser rejeitadas: "As formas de retomadas são, antes e acima de tudo, expressões referenciais no sentido mais geral do termo". E ainda segundo esse autor: "O que se chama comumente de antecedente- a saber, um segmento de texto situado antes do anafórico no texto e tendo com ele uma relação de interpretação ou de correferência - não é, na realidade, um elemento de modo algum indispensável aos funcionamentos das formas de retomadas." (APOTHÉLOZ,2003, p. 57).

Segundo Koch e Marcuschi (1998, p. 174), “A progressão referencial não implica necessariamente a correferência [...] ela podedar-se como uma reconstrução fundada num contexto gerado no interior do próprio texto sem implicar retomada de referentes, mesmo que faça uso de repetição de itens lexicais".

Como vemos, as discussões nesse campo são acirradas. Nesse trabalho, a concepção de anáfora adotada é a mais ampla, uma concepção que se estende para além do nível da sentença, abarcando o discurso.

A seguir, tratamos do uso de três tipos de anáfora em textos desses alunos: anáfora direta, anáfora pronominal sem antecedente explícito e anáfora associativa. 


\subsubsection{Anáfora direta}

A anáfora pronominal direta é uma das estratégias mais usadaspor produtores de texto na progressão do referente.Esse tipo de anáfora é chamado por Cavalcante (2003)Anáfora não-co-significativa e nãorecategorizadora. Conforme a autora:

Sempre se alegou, na Linguística, que as formas pronominais divergiam dasformas lexicais por seu baixo grau de significação, por sua função mais gramatical doque lexical, por seu traço dêitico ou representacional etc. Como, então, sustentar que onome antecedente nominal e o anafórico pronominal são 'co-significativos' se, pordefinição, é a peculiaridade de significados que os distingue? Julgamos mais adequado,por isso, considerar os pronomes pessoais anafóricos como não sendo nemrecategorizadores, nem co-significativos. (CAVALCANTE, 2003, p. 111-112)

Concordamos em parte com os argumentos da autora.É complexo dizer que uma forma "vazia”, ou quase vazia, conforme tratamento dado pela gramática aos pronomes ditos pessoais, ocupe o lugar de uma forma lexical. Mas, se consideramos que as formas de retomada anafóricas, através dos pronomes, não sejam retomadas do referente quanto a todas as suas propriedades, como o fazemApothéloz (1995) e Koch \&Marcuschi (1998) é, sim, possível falar-se em recategorização.

Nos exemplos abaixo,exibimos trechos que ilustramo uso da anáfora direta pelos alunos do PARFOR:

(06) "A escola como tudo na vida tem seus métodos e procura dentro de seus conhecimentos buscar o melhor para avida das crianças, conteúdos que vão somar para o aprendizado que vai formar cidadãos profissionais que irá interagir na vida da sociedade em geral, para que isso aconteça que $a$ criança seja um ser humano responsável ela precisa ser cobrada incentivada a fazer a e dar o melhor de $\underline{\text { si....”. }}$

(07) "[...] Para que o aluno chegue a esse objetivo, ele precisa ser avaliado por um processo de avaliações organizada com a finalidade de obter informações sobre o que ele aprendeu durante o ano letivo".

(8) “A avaliação, por mais completa que seja, dificilmente abrangerá todos os aspectos linguísticos de uma produção, dada a individualidade de cada um, então objetiva-se eleger alguns critérios que orientem os alunos nos aspectos mais críticos.Elatem nesse sentido, mais que uma função técnicoteórica, uma função didática, pois não pode restringir-se ao aspecto gramatical do texto”.

(09) "Desse modo, o processo avaliativo é muito mais abrangedor, cuja atribuição de notas ou conceitos deve estar restrita aos critérios de avaliação que foram analisados e comentados anteriormente com os alunos. É importante que eles tenham conhecimento claro sobre quais aspectos serão avaliados".

Em (6), os pronomes ela e si são retomadas anafóricas da expressão nominal acriança.Em (7), o pronome pessoalele aparece duas vezes para fazer evoluir o referente aluno.

Vemos, assim, que a progressão referencial, utilizando-se de anáfora direta, é uma das estratégias mais usadas pelos alunos do PARFOR para fazerem evoluir o referente, o que está em conformidade com a tendência geral já abordada na Linguística Textual.

\subsubsection{Anáfora sem antecedente explícito}

Passamos a tratar da retomada anáforica sem antecedente explícito, um dos subtipos de anáfora indireta. Schwarz(2000)define dois tipos fundamentais de anáfora indireta: tipos semanticamente fundados e tipos conceitualmente fundados, sendo, conforme a autora, a relação entre âncora e anáfora de extrema importância para a definição de subtipos de anáfora indireta.Nesse tipo de retomada, para atribuir sentido ao pronome anafórico, ou seja, encontrar o referentea que esse pronomeremete, é necessário que o interlocutor mobilize diversos tipos de conhecimentos e estratégias de compreensão, como recorrer a elementosco-textuais, conhecimentos enciclopédicos e esquemas cognitivos fazendo inferências e cooperando para com o produtor a fim de atribuir sentido ao texto. 
(10) “[ [...] Há uma questão política muito forte por trás de toda essa questão, discursos muito bonitos que engana muita gente sem conhecimento da realidade escolar, porque eu não me engano. Os projetos políticos brasileiros são feitos a curto prazo e não se melhora a educação de uma hora para outra, como eles dizem que a educação está no rumo certo [...]”.

(11) "O aluno em sala de aula deve estar informado de maneira qualitativa e de maneira diferente das que ele já viu sobre o que aprender o que eles precisam saber fazer melhor procurar fazer correções e comentários sobre as produções de textos do aluno. Neste momento, procurar oferecer indicações claras para que possam melhorar seu aprendizado”.

Através do contexto, podemos depreender que o pronome eles em (10) não faz referência a um antecedente explícito, mas a um referente extratextual. Através do cotexto, recorrendo ao nosso conhecimento de mundo, é possível inferirmos que o referente do pronome eles é políticos. Essa inferência é possível porque, através de nossos conhecimentos de mundo e conhecimentos enciclopédicos, sabemos que esse é o discurso atual dos políticos para a educação.

Em (11), o pronome eles de imediato parece se referir a um antecedente explícito aluno, expresso anteriormente pelo pronome ele, o que seria uma retomada anafórica sem os atributos do antecedente. Na continuidade da leitura, percebemos que o pronome se refere aprofessores. Isso é possível porque fazemos inferências baseadas em nosso conhecimento de mundo sobre como o professor ensina ou deve ensinar e o que é função do professor. Além disso, a estrutura da língua auxilia na identificação da função do termo aluno. No nível sentencial, esse termo é parte do objeto da sentença "produção de textos de alunos" da oração em que o referenteprofessores não está explícito e é retomado pelo pronome anafórico eles, cuja função gramatical desempenhada no interior da sentença é a de sujeito.Neste caso, essa retomada anafórica sem antecedente explícito exige muita cooperação por parte do interlocutor para construir o sentido do texto. Sem essa cooperação, intencionalmente ou não, estaríamos diante de um texto pouco claro, no qual a implicitude poderia afetar sua compreensão.

\subsection{PROGRESSÃO REFERENCIAL E ANÁFORAS INDIRETAS}

A anáfora associativa (AA) é um subtipo das anáforas indiretas - cf. Koch (2005) e Marcuschi (2005). De acordo com esses autores, aanáfora indireta é geralmente constituída por expressões nominais definidas ou pronomes interpretados referencialmente, sem quelhes corresponda um antecedente explícito no texto. Isso constitui o que denominam processo dereferenciação implícita.Entretanto, essa não é uma visão unânime entre os estudiosos desse assunto. Outra visão da temática defende que a anáfora associativa se constitui nas relações marcadas no léxico. Conforme Marcuschi (2001, p. 222),os autores que defendem essa visão partem do fato de que "A associação seria dada como uma espécie desuposição semanticamente instituída na própria língua e situada no âmbito da competêncialinguística. Isto tornaria a AA uma relação essencialmente léxicoestereotípica”. Esse ponto de vista é defendido pelos partidários de uma concepção estreita de anáfora associativa, como Kleiber (2001) e Schwarz (2000).

Conforme Kleiber, "Os 'todos' que implicam relações metonímicas não são seus dependentes, mas aparecem como indivíduos funcionalmente autônomos" (KLEIBER,2001, p.268, tradução nossa) ${ }^{5}$.

Neste trabalho, adotamos a visão mais ampla de anáfora associativa. Respaldamo-nos, para tal, em trabalhos de Koch (2005; 2002; 2004), Marcuchi (2005), Apothéloz(2003) e Koch e Marcuchi(2008). De acordo com Koch (2005, p. 270),"A anáfora associativa explora relações meronímicas, ou seja, todas aquelas em queentra a noção de ingrediência [...] todas aquelas relações em que um dos elementos pode ser considerado 'ingrediente’ do outro”.

A anáfora associativa está inserida no grupo II-tipos conceitualmente fundados -, dos tipos fundamentais de anáfora indireta, propostos por Schwarz (2000, p.99).

Partindo do que postula Marcuschi(2008) sobre uma das características da anáfora associativa, que é ter uma motivação ou ancoragem no universo textual, e do que defendem Koch e Elias (2010, p.136):

\footnotetext{
5“Les 'touts' que impliquent les méronymes ne sont pás dépendentes de leurs, mais apparaissent comme étant des individus fonciéremente autonomes" (KLEIBER,2001, p.268).
} 
Anáforas cujos antecedentes não podem ser apontados no texto, mas devem ser conferidos com base em âncoras textuais [...]. As anáforas indiretas podem ser constituídas com base, por exemplo, em modelos cognitivos, inferências ancoradas no mundo textual ou em relações semânticas inscritas nos sintagmas nominais definidos, particularmente as relações meronímicas.

Não se pode falar de progressão do referente como se falou até então; também não se pode negar uma estreita relação entre o referente que tem uma ancoragem no universo textual e a progressão referencial, uma vez que sua presença no texto se deve à associação com itens relacionados semanticamente e que se encontram no mesmo universo textual. Portanto, a expressão 'referenciação implícita', empregada por Koch (2005) e Marcuschi (2005),exprime bem esse tipo de relação.

Partido do que foi colocado até aqui e da Literatura especializada sobre a temática, apresentamos, a seguir, duas propriedades das anáforas associativas: a) na anáfora associativa não há relação de correferencialidade, mesmo que a expressão anafórica parta de uma âncora no texto e b) sua interpretação referencial é feita exclusivamente com base em elementos conhecidos (dados) e que se associamno universo textual ou extratextual (cotexto e contexto).

A seguir, mostramos como os alunos do PARFOR-LETRAS fazem uso desse recurso em seus textos.

(12) "Uma boa parte do sistema a educacional está preocupadocom a quantidade, isto é, a aplicação de investimento nessa área vem muito mais se houver bons resultados de aprovação".

A expressãonessa área, que aparece no exemplo imediatamente anterior,sem uma relação anafórica explícita, mas que encontra implicitamente relação em elementos do cotexto, como escola, sistema educacional, é uma anáfora associativa. Marcuschi (2005, p. 59), respaldado em Schwarz (2000), afirma que: "As anáforas indiretas podem ser constituídas com base, por exemplo, em modelos cognitivos, inferências ancoradas no mundo textual ou em relações semânticas inscritas nos sintagmas nominais definidos, particularmente, as relações metonímicas (relações parte-todo)".

(13) “O governo vem investindo em políticas educacionais visando a melhoria da educação pública. Uma das políticas atuais é a correção de fluxo, uma política que está sendo implantada para diminuir o índice de evasão e reprovação escolar".

A expressão uma das políticas atuais, nesse texto, está inserida semanticamente no conjunto políticas educacionais. Percebemos que o autor não diz que tipo de política trata, parece contar com a cooperação de seu leitor, fazendo-o lembrar de que estar tratando de políticas educacionais, isto é, parte do princípio de que deve estar no esquema cognitivo de seu leitorpolítica educacionais, por isso, provavelmente, acredite que não precisa explicitar a expressão. Expressões como essas constituem o que Charroles (1990) chama de anáfora associativa, uma vez que não existe uma relação de identificação total entre as referências, isto é, entre o nome anterior e a sua retomada anaforicamente.

(14) "Mas, hoje, essa parte integrante da política, não olha para esse lado, eles visam apenas o lucro, o sistema monetário”.

Em (14), o pronomeeles se refere a essa parte integrante da política,o que torna possível a associação é o senso comum segundo o qualos políticos, de uma maneira geral, estão mais preocupados em ganhar dinheiro do que com o bem-estar da população.

Em (15), excerto posterior, a anáfora associativa é dele, cuja âncora énós professores. Percebe-se que, nesse ponto, a associação apresenta um pouco mais de complexidade semântica, pois, além do leitor precisar do conhecimento de mundo sobre a função do professor, precisa também inferir que o temo dele funciona aí como 'nossa',ou seja, o leitor precisa fazer duas operações cognitivas para inferir e decifrar a significação dos termos para evoluir e compreender a mensagem que o produtor do texto quer transmitir.

(15) “A avaliação, apesar da responsabilidade de nós professores, não deve ser considerada função exclusiva dele. Delegá-la aos alunos em determinados momentos, é uma condição didática necessária para que construam instrumento de auto-regulaçãopara as diferentes aprendizagem”. 
Na literatura, foi comum, durantealgum tempo, o entendimento de que a anáfora indireta era manifestada por expressões definidas, sendo rara sua ocorrência através de pronome, conforme postula Marcuschi (2001a, p.225): “A realização da $A I$ [anáfora indireta]se dá normalmente por elementos não pronominais, sendo rara sua realização pronominal”.

Com o avanço de estudos na área, alguns pontos foram revistos. Marcuschi (2005) acrescentou o uso de pronomes às expressões definidas, propostas por Schwarz (2000), e reviu a questão da raridade proposta por ele anteriormente.

As ocorrências de pronomes funcionando como anáfora associativa e anáfora sem antecedente explícito, que constituem subtipos de anáfora indireta,vêm reforçar as ideias deApothéloz (2003, p. 78), segundo as quais: "[...] o referente da anáfora associativa pode ser dotado, se tiver a mesma designação, de um grau de evidência tão alto que nada impede que o anafórico que o designa seja um simples pronome”; e de Marcushi (2005), ao acrescentar expressões pronominais à conceituação de anáfora indireta de Schwarz (2000), como podemos conferir abaixo:

No caso da Anáfora Indireta trata-se de expressões definidas [e expressões pronominais] que se acham na dependênciainterpretativa em relação a determinadas expressões [ou informações constantes] da estrutura textual precedente [ou subsequente] e que tem duas funções referenciais textuais: a introduçãode novos referentes (até aí não nomeados explicitamente) e acontinuação da relação referencial global”. (MARCUSCHI, 2005, p. 59)

Para finalizarmos, é interessante termos em mente que ainda há muitoestudo a ser feito no campo das anáforas indiretas, especialmente da associativa e que as distinções semânticas são tênues a ponto de tornarem difíceis algumas conceituações.

Conforme se pode perceber, os alunos, nos textos aqui referidos, fazem uso frequente da anáfora indireta. Sabemos que apesar de este ser um fenômeno legítimo e muito utilizado na língua, é mais recorrente em situações informais de comunicação, de forma que não se espera muitas ocorrências desse fenômeno em textos de natureza formal, uma vez que, nesse tipo de texto, a explicitude e alinearidade são caraterísticas fundamentais e na anáfora indireta, conforme postula Marcuschi(2005, p.58), “A textualização não se dá como um encadeamento linear de elementos,de modo que a própria noção clássica de coerência fica afetada”. O uso desse tipo de anáfora nos textos desses alunos, possivelmente, está ligado a pouca funcionalidade desses textos em seu cotidiano e ao pouco domínio da escrita no gênero acadêmico.

\section{CONSIDERAÇÕES FINAIS}

A preocupação primeira deste trabalho foi verificar como os alunos do PARFOR-Língua Portuguesa estavam construindo o referente e como em seus textos estavam evoluindo os objetos-de-discurso.

A nossa pesquisa revelou que a reiteração através de expressões nominais e a anáfora direta são as estratégias mais utilizadas na progressão referencial. Essas características são comuns também à oralidade. Sendo assim, a nossa hipótese inicial é parcialmente confirmada quando dizíamos que possivelmente a problemática enfrentada na escrita por esses alunos estaria relacionada a um contato precário que eles tiveram com a escrita no gênero acadêmico. Como se pode perceber, ao longo dos exemplos, parece existir dificuldade por parte dos autores desses textos para fazerem evoluirreferentes, quando o fazem, parece estarem diante de um texto oral, onde há lugar para vários graus de implicitude e regras análogasàquelas utilizadas no discurso cotidiano, como a repetição.

Essa pesquisa, até aqui, serviu-nos como diagnóstico,orientando-nos sobre como tratar a questão, a fim de buscar estratégias que pudessem auxiliar esses alunos no sentido de levá-los a apreenderem novas formas de fazerem evoluir o referente. Em Pereira e Koch (2014), propomos algumas atividades que podem ser úteis ao domínio de estratégias de progressão referencial.

Por fim, ficaremos felizes se esse trabalho puder contribuir com as pesquisas que vêm se desenvolvendo sobre a temática ou com o aprendizado dos sujeitos envolvidos. 


\section{REFERÊNCIAS}

APOTHÉLOZ, Denis. Papel e funcionamento da anáfora na dinâmica textual. In: CAVALCANTE, Mônica; RODRIGUES, Bernadete Biasi; CIULLA, Alena (Org.) Referenciação. São Paulo: Contexto, 2003.p. 53-84.

APOTHÉLOZ, Denis; REICHLER-BEGUELIN Marie-José. Construction de la reference et strategies de designation. In: BERRENDONNER, Alain; REICHLER-BEGUELIN, Marie-José (Ed.).Du sintagme nominal auxobjets-de-discours. Neuchâtel: Université de Neuchâtel, 1995. p. 227-271.

CAVALCANTE, Mônica Magalhães. Expressões referenciais - uma proposta classificatória. Cadernos de Estudos Linguísticos, 44, Campinas, IEL/Unicamp, p. 105-118, 2003.

CHAROLLES, Michael. L’anaphore associative.Problémes de delimetation.Verbum, n.13, v.3, p. 19-148, 1990.

HALLIDAY,Michael Alexander Kirkwood. An introduction to functional grammar. London: Edward Arnold, 1985.

KLEIBER, Georges.L'anaphore associative. Paris: Presses Universitaires de France, 2001.

KOCH, IngedoreGrunfeld Villaça.O texto e a construção dos sentidos. São Paulo: Contexto, 2007.

.Introdução à linguística textual: trajetória e grandes temas. São Paulo: Martins Fontes, 2006.

.Léxico e progressão referencial. In: RIO-TORTO, Graça; SILVA, Fátima; FIGUEIREDO, Olívia

(Org.). Estudos em homenagem ao Professor Doutor Mário Vilela. Porto: Faculdade de Letras da Universidade do Porto, 2005. p. 263-276.

O texto e a construção dos sentidos. 7.ed. São Paulo: Contexto, 2003.

Desvendando os segredos do texto. São Paulo: Cortez,2002.

A inter-ação pela linguagem. São Paulo: Contexto, 1992.

Texto e coerência. São Paulo: Cortez, 1989.

KOCH,IngedoreGrünfeld Villaça; ELIAS, Vanda Maria. Ler e escrever: estratégias de produção textual. 2. ed., Contexto, São Paulo, 2010.

Ler e compreender: estratégias de produção textual. 3. ed. São Paulo: Editora Contexto, 2009.

.Interferências da oralidade na aquisição da escrita.Trabalhos em Linguística Aplicada,v. 30, Campinas, IEL/Unicamp, p.31-38, 1997.

KOCH, IngedoreGrunfeld Villaça; MARCUSCHI, Luiz Antônio. Processos de referenciação na produção discursiva. DELTA, v. 14, p.169-190, 1998.

LIMA, Maria Luiza Cunha. Artigo indefinido e anáfora.Cadernos de Estudos Linguísticos, v. 44, Campinas, IEL/Unicamp,p. 133-141, 2003.

MARCUSCHI, Luiz Antônio. Anáfora indireta: o barco textual e suas âncoras. In:KOCH, Ingedore V; MORATO, Edwiges Maria; BENTES, Anna Christina. (Org.). Referenciação e discurso. São Paulo: Contexto, 2005. p. 53-101.

.Anáfora indireta: o barco textual e suas âncoras. Revista Letras - UFPR, Curitiba, n. 56, p. 217-258. jul./dez. $2001 \mathrm{a}$.

Letramento e oralidade no contexto das práticas sociais e eventos comunicativos. In: SIGNORINI, Inês. (Org.).Investigando a relação oral/escrito e as teorias do letramento. Campinas: Mercado das Letras, 2001b. p. 23-74. 
MILNER, Jean-Caude. Reflexões sobre a referência e a correferência. In: CAVALCANTE, Mônica; RODRIGUES, Bernadete Biasi; CIULLA, Alena (Org.). Referenciação. São Paulo: Contexto, 2003.p. 85-130.

MONDADA,Lorenza. Construction des objets de discours et catégorisation: une approche des processus de référenciation. Tradução: Mônica Magalhães Cavalcante.Rev. de Letras, v. 1/2,n.24, p.118-130 jan/dez. 2002. 36, 2001.

Gestion du topic et organisation de la conversation. Cadernos de Estudos Linguísticos, Vv. 41, p. 07-

Verbalization de l'éspace et fabrication du savoir: approchelinguistique de

laconstructiondesobjetsdudiscours.Lausanne: Université de Lausanne, 1994.

MONDADA, Lorenza;DUBOIS, D. Constructiondesobjets de discoursetcatégorisation: une approche dês processus de référentiation.In: BERRENDONNER Alain;REICHLER-BEGUELIN, Marie-José (Ed.). Dusintagme nominal auxobjets-de-discours.Neuchâtel: Université de Neuchâtel, 1995. p.273-305.

PEREIRA, Antônia Alves; KOCH, Ingedore Grunfeld Villaça. Ensino-aprendizagem: referenciação e progressão textual no ensino superior. Trab. Ling. Aplic., Campinas, n 53, 1 p. 183-199, jan./jun. 2014.

SCHWARZ, Monika. Indirekteanaphern in texten.Tübingen: Niemeyer, 2000.

Recebido em 15/og/2014. Aprovado em 13/o2/15. 